Bruno Deffains ${ }^{1}$, Samuel Ferey ${ }^{2}$

\title{
Litigations in Labor Law: Intuitive vs. Reflective Judgements?
}

\section{Introduction: Economic analysis of litigation}

A growing topic in Law and Economics is the organization of the judicial system. Models relating to the outcome of trials attempt to describe and explain the choice of the parties between litigation and settlement. The first analysis of this nature goes back to 1972 with the publication of Landes' article entitled »An Economic Analysis of the Courts « (Landes, 1971). Further studies in this area have insisted on the strategic parties' behavior (Cooter and Rubinfeld, 1989).

Initial models of legal conflicts developed in the seventies (Landes 1971; Gould 1973) did not really propose to describe negotiations which may have occurred before the judge's decision. The aim of their authors was rather to identify the incentives of the parties as rational agents to solve a dispute and explain why negotiations fail in certain cases, thus requiring the intervention of a judge. The answer to this question comes from an excess of optimism on behalf of the parties concerning their chances of winning the trial, i.e. a misperception of the surplus emanating from negotiation. Even though these models do give a reasonably convincing explanation of how disputes are settled out of the court, they remain very vague as to the way in which those concerned form their expectations as to the outcome of the trial and as to why they are over-optimistic.

This is probably why, most of authors prefer to insist on the strategic nature of negotiation and choose to represent litigation as games under imperfect information. It is no longer necessary to suppose that what the parties believe is systematically biased in order to explain the outcome of conflicts through legal proceedings. The existence of informational asymmetries is indeed at the root of differing beliefs as to the outcome of a trial and final decisions may be the result of optimal negotiation strategies of the two parties. In the context of a litigation between a plaintiff and a defendant, game theory enables to give a precise idea on the outcome of strategic interaction, rendered even more complex as one of the actors may hold personal information or present characteristics the other party cannot observe. By looking at negotiation process, the suggested approach already goes one step further than those of Landes and Gould. Henceforth, the beliefs of the parties are consistent in equilibrium in the sense that they commit no systematic errors (subjective probability matches objective frequency) but the likelihood of the negotiation failing is still not zero. Compared to the optimistic models, strategic ones generally offer a richer description of legal process whether or not there is a settlement between the parties. However, there is still a problem with strategic models because they

1 BETA-REGLES, University of Nancy 2 and CNRS, Bruno.Deffains@univ-nancy2.fr. Adress for correspondance : BETA-REGLES, University of Nancy 2, 13 Place Carnot, CO $n^{\circ} 26,54035$ Nancy Cedex.

2 BETA-REGLES, University of Nancy 2 and CNRS, Samuel. Ferey@univ-nancy2.fr. Adress for correspondance : BETA-REGLES, University of Nancy 2, 13 Place Carnot, CO $n^{\circ} 26,54035$ Nancy Cedex. 
need to emphasize the existence of asymmetries of information ${ }^{3}$. However, a different reason why parties' expectations may diverge emerges from experimental evidence, pointing to the fact that disputants make self-serving valuations of their probability to win the case. There is a systematic tendency for one to believe to have better chances than his or her counterpart (Loewenstein, Issacharoff, Camerer and Babcock, 1993). The recent researches about litigations introduce the psychology of litigants and actors of conflicts resolution. This brief overview of the literature concerning economic analysis of litigation seems to suggest that psychology of the players needs to be taken seriously.

The present paper explores a way by which Behavioral Economics concepts as heuristics may be introduced into economic analysis of litigation. According to us, Behavioral Law and Economics makes it possible to take account of a crucial feature of legal phenomenon namely the fact that uncertainty in the law makes the outcome of the adjudication difficult to predict and hence supports the divergence of the parties' subjective expectations. We introduce first the concept of heuristic and we explain why it may be understood from a twofold legal and economic point of view (2. Heuristics as economic and legal devices). From the legal point of view, heuristics are some cognitive process and devices, which help the agents to interpret the law. As such, they are a key-element of their assessment of probability to win. From the economic side, the agent may use heuristic to assess the probabilities to win or lose the case. Then, we illustrate our insights with the data from the French labor litigation (3. Insights from French labor law). Our analysis is still in progress but our aim it to propose some insights in order to give an example of the manner by which such a framework may be applied to an empirical field.

\section{Heuristics as economic and legal devices}

The traditional economics of legal litigation (»optimistic models«, »strategic ones «) insists on two key features of litigation: different expectations of the parties on the outcome of the litigation (probabilities to win the case, valuation of gain etc.) and information. However, this traditional approach has actually difficulties to explain why every litigation is not settling out of courts ${ }^{4}$. That is the reason why the traditional models are often compelled to add additional hypothesis, which badly fit with the rational action theory: the ideas of »optimistic agent « or »self-serving bias « illustrate very well this feature. And behavioral law and economics perspective may be useful in order to analyze and explain legal litigations.

3 Of course, the parties may derive optimistic beliefs from some private information they possess about the likelihood to win in court. However, the presence of discovery rules that oblige parties to lay down their private information before the trial may facilitate settlement. Even so, parties may still be uncertain about each other's investments in the trial, which affect the probability of winning.

4 As we have said, it is very difficult for the traditional framework to explain the different expectations of each side of the dispute and the possible errors concerning the assessment of the probabilities. Indeed, rational action theory assumes that individuals make no systematic error on the probabilities of risky events. 
In this part, we would like to give some insights about how and why, according to us, behavioral law and economics may be useful in the analysis of litigation. Being a situation of uncertainty (uncertainty of the outcome of adjudication), the litigation is an obvious topics for behavioral economics. But as far as law is concerned, it seems to us that there is a deeper point which deals with the very nature of a legal conflict: the uncertainty of adjudication deals with the meaning of the law that is to say with a judgment: from legal side, the litigation may be understood as a conflict about different individual judgments and from economic side - decision theory -, litigation comes mainly from different expectations about the case (in terms of gain or of probabilities for example). It seems to us that the concept of heuristics is particularly useful in this context because it makes it possible to link the two sides of litigations, economic and legal: heuristics are clearly both a cognitive process of judgment and a cognitive process of assessment of probabilities of an uncertain event. Thanks to this concept, it could be possible to describe more accurately the specific interaction of legal litigation.

We mainly focus here on the concept of heuristics and bias. As behavioral economics scholars assert, agents use heuristics when they face uncertainty (Kahneman and Tversky, 1982 for example). The heuristics are cognitive processes used more or less consciously to assess the probabilities of uncertain events. Usually, three heuristics are distinguished: availability heuristic, anchor heuristic and case-based decision. The availability heuristic induces that people »tend to think that risks is more serious when an incident is readily called to mind « (Jolls, Sunstein, Thaler, 2000, p. 5); the anchoring may take place when people use an initial value - whose origin may be irrational - as the ground of their judgments; finally, the case-based decisions may arise when people reason by calling in mind a past case in order to make a judgment about a new case. As it is well known, the key-element of the heuristics literature is to show that the use of such rules of thumb may induce systematic errors on the true probability of an event. More generally, we may consider the classical bias (optimistic bias, hindsight bias and self-serving bias) as such rules of thumb: people tend to be optimistic and an overconfidence in risk judgment may appear, they tend to like status-quo or they may overestimate the probability of an even simply because this event has occurred.

As far as law and economics is concerned, uncertainty deals with the decision of the judges concerning the legal cases. According to us, the point here is that adjudication crucially depends on the interpretation of law by judiciary. The legal side of the problem of litigation is thus a conflict of interpretation on the meaning of legal norms. From the legal point of view, the true nature of a legal dispute is before all due to the fact that parties make some divergent interpretations about what law says. By insisting on this feature, we actually hold a point of view, which fits well with contemporary legal theory which considers law as mainly an interpretative and hermeneutic practice ${ }^{5}$.

5 See for example: Troper 2000; Ricoeur, 1995; Frydman 2005. Actually, the debates concerning the nature of legal interpretation are numerous. However, a lot of legal theory debates deal now with the consequences of the « interpretative turn » on the nature of the law, the role and the power of judiciary or the methods of legal interpretation. 
There are a lot of reasons why divergent interpretations may arise. This is the case notably because legal rules are never clear by themselves ${ }^{6}$. And contemporary legal theory acknowledges that law is deeply an interpretative process (Frydman, 2005): the topics of the methods of interpretation, the nature of interpretation and the consequences of the judges ability to attribute - or to determine - a specific meaning to a law are now the heart of the legal theory (Troper, 2000). Economists who are interested in law need to take account this feature to analyze litigation: it is precisely because the meaning of a norm needs always to be reconstruct by judiciary that conflict may arises. This feature has some huge consequences on the economic analysis of litigation.

From the economic side of the problem, this means that conflict arises notably from the different expectations of agents on the meaning of the law ${ }^{7}$. As law is always unclear, it is possible for the agents to misperceive its true meaning (at least, the meaning that the judge will attribute to the norm and the manner by which the judge will apply the law to a particular case). Heuristics may be used to describe some aspects of the cognitive processes by which people will interpret legal norms and by which such a judgment - more or less intuitive - will be the grounds of their assessment of the probability to win or to lose the case.

Finally, from a law and economics point of view, the two topics ( $\mathrm{a} /$ the meaning of law - and conflict about this meaning - and b/ the assessment of probabilities) are the two sides of a same coin: the cognitive mechanisms by which people make judgments about the meaning of law and so assess the probabilities to win or lose the case. It is precisely to analyze these two aspects in a unique framework that the concepts developed by behavioral law and economics are useful. Indeed, the concept of heuristics for example draws a general framework to analyze both the individual judgment - legal theory - and the mechanisms by which they assess the probabilities of an event - decision theory ${ }^{8}$.

Therefore, heuristics and bias in litigation process field may be understood as a lot of cognitive devices which describe how people interpret law, how they interpret their own case compared with the meaning of law ${ }^{9}$. In other words, heuristics are both a mechanism by which people interpret the law and assess the probability that they are

6 For example, legal norms are often general and need to be applied to a particular case. The deduction from a general legal statement induces a cognitive process of interpretation to know to what extend the case fits with law and to determine the meaning of law. The keyfeature of this process is obviously the judge insofar as he is the legitimate authority to determine the meaning of law.

7 If laws were completely clear and determined, people never go to courts and a settlement will always be possible.

8 More generally, the title of the classical book from Kahneman and Tversky is Heuristics and Bias : Judgment under uncertainty. It is very clear that what Kahneman wants to build is a general theory of judgment that is to say a theory of the cognitive mechanisms by which people make some judgments and how these judgments may influence rational behavior.

9 For example, Babcock and Leowenstein find that people may interpret available information about a case in really different manner (Babcock and Leowenstein, 1997). One important element is when they are informed beforehand the role they will play: they tend to interpret the information in a more favorable way when they know which they will be in the trial than when they do not know. For Jolls, dealing with hindsight bias, a bias induces individuals to « interpret » in a certain way the information available (Jolls, 2004, p. 14). 
$»$ right « or »wrong «. One consequence of this point is that the reverse is also true: if heuristics - judgment and interpretation - are able to influence the individual assessment of probabilities to win or to lose the case, that means also that a knowledge of the true probabilities may influence the individual judgments about the meaning of the law. In other words, it seems to us that calculation and interpretation are not competing but are more or less complementary. If for example, an agent thinks that a norm has a specific meaning and if he becomes aware that actually no case belonging to this category is ever decided by courts as he expects, we may suppose that he will change his judgment and his belief about the meaning of this rule. In other words, a better knowledge of the probabilities reinforces the rationality and may influence also the judgment ability of the individuals. The French labor law field illustrates very well that it could be interesting to consider heuristics and bias from this twofold point of view, interpretation/rationality.

\section{Insights from French labor law}

According to French labor law, the employers can fire workers for only two reasons (art L. 122 and L. 321-1 of the French Labor Code): »economic reason« (redundancy, art. L. 321-1) and »personal reasons « (dismissal) (art. L. 122) ${ }^{10}$. Employers may breach the employment relationship for economic reason when the break of the contract is »notably [due to] economical difficulties or technological change« (art. L. 321-1). They also may break the contract for dismissal when the breach of contract is due to a »serious and real cause« (art. L. 122). Hence, there are two different legal norms, which organize the break of the employment relationship by the employer. The two rules are very different insofar as dismissal is based mainly on subjective reasons (the features of the employee) while redundancy is concerned only with financial or economic difficulties of the firm or technological change ${ }^{11}$.

It is often said that French courts very strictly interpret redundancy. By »strictly interpret «, we mean that it is said to be very difficult for employers to use redundancy norms in

10 We translate the French words «licenciement pour motif personnel » by dismissal and « licenciement pour motif économique» by « redundancy». Obviously, the contract may be broken by the employee (« démission ») or by mutual agreement. In the following, we focus only on the unilateral decision of the employer.

11 However, each of the two norms needs interpretation to be applied to particular cases. Indeed, people need to know what »economical difficulties « or »technological change « really means. The most difficult task is obviously how interpret the term »notably«. That is why the role played by judiciary - and notably the French Civil Supreme Court (Cour de cassation) - is so important in labor litigation. For example, all along the 1990' and the 2000', French Civil Supreme Court has largely modified the content of the L. 321-1 article and what people should understand behind the words of the Code's article (for example see Cass. Soc., April 1 ${ }^{\text {st }}, 1992$; April 5, 1995 ; January 18, 2006). Before 1992, Supreme Court interpreted the redundancy as concerned by the competitiveness of firm, then, it decided that the « interest of the firm » was the criteria of redundancy. In 1995, Supreme Court has defined redundancy by a more restrictive criterion, Wacquet, 2005). Lastly, we may notice than dismissal is defined on purely subjective elements while redundancy is defined on feature which appears as more objective (as for example the financial difficulties of the firm). 
order to end the employment relationship (Blanchard and Tirole, 2003). The analysis of data available seems to suggest that employers use the two procedures strategically: employers use dismissal in order to hide some redundancy cases. Such a huge substitution phenomenon is described for example by Cahuc and Kramarz as by Tirole and Blanchard ${ }^{12}$ or by the DARES reports (DARES, 2003) who provide a lot of convincing evidences ${ }^{13}$.

In a neoclassical framework (where people - firms - are supposed to maximize their utility - profit), it seems easy to explain this phenomenon. As the redundancy is said to be strictly interpreted by courts, employers tend to prefer using dismissal and avoid the risk to be fined by court. The result is clearly that dismissal does not fit anymore with the proper reason of the breach of the employment relationship. In other words, employers seem to be typically rational since they maximize their utility by a strategic use of the labor laws. And for Cahuc and Kramarz or Tirole and Blanchard, it is less the differential of cost between dismissal and redundancy than the uncertainty of redundancy litigation due to the strict control by judiciary - which is the key-element of the phenomenon (Cahuc and Kramarz, 2004, p. 150-151) ${ }^{14}$. According to them, French judges have too much power to decide if redundancy is unfair or not and this control induces employers to substitute dismissal and redundancy. That is the reason why they criticize so strongly the role played by judge in the regulation of labor relationship (Blanchard and Tirole, 2003).

As such, this presentation seems suggesting. However, a straigh analysis of the labor litigation implies to contradict this thesis ${ }^{15}$. Indeed, we face a crude paradox: by substituting redundancy and dismissal, employers actually choose the most risky procedure. The probability for an employer to be sued by an employee after a redundancy is much greater than the probability to be sued after a redundancy ${ }^{16}$. The data available is thus quite puzzling concerning the hypothesis of substitution or at least concerning the rati-

12 Blanchard and Tirole, 2003 ; Cahuc and Kramarz, 2004, p. 150.

13 In order to give an insight of the phenomenon, basic empirical data is sufficient: while in 1994, there were about 500000 redundancy and 350000 dismissal, in 2002, there were 250 000 redundancies and 530000 dismissals (Munoz-Serverin, 2005, p. 19). In ten years, the share of dismissals continuously raised and the share of redundancy continuously fell in huge proportionsHowever, some evolution of the market labor itself may explain the discrepancy between the two procedures. For example, the different sectors do not use in the same proportion the two procedures and the substitution may be due to the evolution of the share of the sectors themselves within French economy.

14 Blanchard and Tirole consider that the direct costs of dismissal or redundancy are low. They write, «the direct costs [of dismissal or redundancy] are relatively small » (Blanchard and Tirole, 2003, p. 42). The main costs are indirect and come from the risk to be fined by courts.

15 In a nutshell, labor litigation in France is mainly individual conflicts. There are really few collective conflicts. Most of individual dispute deal with the breach of labor contract $(65 \%$ of the total number of disputes) and in $98 \%$ of the cases, the plaintiff is the worker. Two other features are crucial. First of all, half of the cases are settled out of courts. For those, which are effectively judged by courts, Blanchard and Tirole consider that the probability of success for the plaintiff - the worker - is near 80\% (Blanchard and Tirole, 2003).

16 Statistical data from the French Justice Department indicates that more than $25 \%$ of dismissals are litigated by employees while only 1,5\% of redundancy are (Munoz-Perez, Serverin, 2005) Unfortunately, the data of the employers fined by courts at the end of the trial are not available. But other empirical data (notably the general rate of success for plaintiff) seems to suggest that the rate of litigation may be considered as a quite good proxy of the probability to be fined. 
onality of such a substitution in terms of maximization of expected profit. This paradox motivates our research in terms of behavioral law and economics. The data that we are analyzing suggests the neoclassical explanation of the evolution of labor law litigation is perhaps not so obvious as it appears at first sight. Our main question is to wonder whether employers could not be biased in their assessment of probability to be fined by courts? More precisely, it seems to us that it is possible that employers tend to overestimate the probability to be fined for redundancy and underestimate the risk to be fined for dismissal. These biases ${ }^{17}$ in their judgment may explain the strange use of labor law in France.

The time is gone to link the different elements of our framework in a coherent vision of bias concerning French labor litigation. As we have said, heuristics and biases are here considered as describing a twofold process: the one by which people interpret the law and the one by which people make their expectations about events (being sued, being fined etc.). If our link between interpretation and rationality holds, the huge rate of litigation of dismissal induces that people make a lot of error on the true meaning of »dismissal ${ }^{18}$. They badly interpret the law because they overestimate the relevance of their interpretation of dismissal laws and underestimate their interpretation of redundancy. This feature has a lot of consequences on the analysis if we suppose, like Cahuc or Tirole, that some cases of redundancy are hidden under dismissals. Indeed, employers are induced to prefer dismissal - because of their belief about the law - which is the more risky procedure ${ }^{19}$.

The question arises to know how employers make their expectations about the meaning of law and so why such a phenomenon of overconfidence may appear. One way to explain it is that employers use availability heuristics in order to assess the probability to be sued and fined for redundancy. One of the important point could be the substantive differences between the two laws. As dismissal is concerned, the legal elements needed are highly subjective: the »fairness « of dismissal is grounded on subjective data as the specific features of the workers, his attitude, or even his fault. On the contrary, redundancy is defined by elements, which may appear being more objective: redundancy is independent from the peculiar features of the employee and makes reference only with economic, financial or technical arguments.

This strong feature of law may have some huge consequences on the manner by which employers interpret labor laws. Indeed, in case of redundancy, it may be easier to call in mind an example of an employer fined because of unfair redundancy. The analogical reasoning may be easier in case of redundancy and the fact that employers call in mind some cases of employers fined for unfair redundancy may induce them to

17 As we focus on bounds or rationality, we do not deal with the two other bounds used by behavioral economics namely bounds of self-interest (the agents do not always pursue their own interest) and bounds of willpower (the agents are not always able to respect their commitments, (Thaler, 1996).

18 In a sense, compared with the high rate of litigation in case of dismissal, there are here »too much « agreement between employers and employee in case of redundancy. It is the consequence of the fact that they interpret the law too strictly compared to legal adjudication.

19 And by supposing notably that the outcome of the trial is the same in both cases. 
overestimate the probability to lose the case. Symmetrically, as dismissal is defined on subjective features of the employee, people do not call in mind an example that fits perfectly with their particular case. Even if they know the objective probabilities to be sued, they underestimate the risk because they consider their particular case as unique.

Our research of the origins and possible explanations of cognitive bias is still in progress. But our main point was to link explicitly the topic of the feature of law, the nature of the interpretation process and the cognitive skills of people. In a way, according to us, the cognitive abilities of people are the roots of the mechanisms by which they interpret the law and thus form their expectations. From this point of view, labor law seems to be a very relevant field of research. The next step is obviously to build some empirical procedures in order to be able to test such cognitive effects.

\section{Conclusion: Judicial process: debiasing law?}

To conlude, we just would like to say some words about debiasing (Jolls and Sunstein, 2006). The question is well-known: even if biases exist, why such biases could be persistent trough times. Indeed, if interpretation and assessment of probability are the two faces of a same coin, why the knowledge of the true probability to be sued and fined does not correct the error of interpretation made by agents. For example, why the low rate of litigation concerning redundancy does not induce employers to consider that they are wrong when they strictly interpret redundancy and that they »self-restraint « in the interpretation of redundancy. Asking this question implies to deal with a very classical topic within behavioral law and economics literature. Following Kahneman (for example Kahneman and Frederick, 2002, p. 51), it is possible to distinguish two families of cognitive operations, intuitive one (called system 1) and reflective one (called system 2). While the later is more deliberate, conscious and controlled, the former is more immediate and automatic. Such dual-process theories seem to be particularly useful concerning labor litigations since one side of the contract may be an organization, which has huge access to information and large skills to compute it. However, it seems to us that system 2 does not always detect and correct the errors of system 1 .

In law and economics, this crucial distinction has a lot of consequences because it deals with the ability for law - or legal procedure - to »debiase « individuals ${ }^{20}$. The key-point seems to be the role of procedural aspects in the ability for judiciary to make it possible to correct the systematic judgment's errors due to cognitive bounds. Hence, every analysis of litigation thanks to heuristics and bias needs to deal with this topic insofar as it is necessary to show why the judiciary is unable to provide some corrective devices (Jolls, 2004, p. 24-25). In our case, we may notice that the rate of settlement out of courts is higher in the case of dismissal than in case of redundancy (Munoz-Perez, Serverin, 2005). This fact may imply that actually, judiciary do not correct the false expectations of people insofar as the hidden redundancy may be solved out of court by private transaction. Thus, judiciary does not provide coherent signals by not

20 For a presentation and a discussion of this topic, see for example: Jolls, 2004; Jolls and Sunstein, 2006. 
providing sufficient precise interpretation of the boundaries of redundancy and dismissals. To be provocative, we would say, contrary to Blanchard and Tirole, that some aspects of labor law in France is inefficient precisely not because judge has too much power but because he is not powered enough.

\section{Bibliography}

Amselek Paul (ed.). 1995. Interprétation et droit, Bruylant, Bruxelles.

Babcock, Linda, George Loewenstein and Samuel Issacharoff. 1997. »Creating Convergence: Debiasing Biased Litigants «, Law and Social Inquiry, 22:913-26.

Cahuc Pierre et Kramaz Francis. 2004. De la précarité à la mobilité : Vers une assurance sociale professionnelle, Rapport au Ministre de l'Emploi, du Travail et de la Cohésion sociale, décembre.

Cooter Robert D. and D.L Rubinfeld. 1989. »Economic Analysis of legal Disputes and their Resolution«, Journal of Economic Literature, 27: 1067-1097.

Dares. 2003. »Les nouveaux usages du licenciement pour motif personnel«, Premières synthèses-DARES, Juillet, 28: 1-8.

Frydman, Benoît. 2005. Le Sens des Lois, Bruylant, Bruxelles.

Gould J.P. 1973. »The Economics of Legal Conflicts«, Journal of Legal Studies, 2: 279-300.

Jeammaud Antoine (ed.). 2005. Le Droit du travail confronté à l'économie, Dalloz, Paris.

Jolls, Christine, Cass Sunstein et Richard Thaler. 1998. »A Behavioral Approach to Law and Economics «, in ed. Cass R. Sunstein, Behavioral Law and Economics, 13-58, Cambridge University Press, Cambridge.

Jolls, Christine. 2004. »Behavioral Law and Economics«, Economic Institutions and Behavioral Economics Conference, Helsinski, June.

Jolls, Christine and Cass R. Sunstein. 2006. »Debiasing Through Law, « Journal of Legal Studies, 35:199-241.

Kahneman, Daniel and Shane Frederick. 2002. »Representativeness Revisited: Attribute Substitution in Intuitive Judgment, « in Heuristics and Biases: The Psychology of Intuitive Judgment, ed. Thomas Gilovich, Dale Griffin and Daniel Kahneman, 4981, Cambridge University Press, Cambridge.

Kennan J. and Robert Wilson. 1993. »Bargaining with Private Information«, Journal of Economic Literature, 31: 45-104.

Landes, William M. 1971. »An Economic Analysis of the Courts«, Journal of Law and Economics, 14: 61-107.

Loewenstein, George, Samuel Issacharoff, Colin Camerer and Linda Babcock. 1993. »Self-Serving Assessments of Fairness and Pretrial Bargaining, « Journal of Legal Studies, 22:135-59.

Munoz-Perez Brigitte and Evelyne Serverin. 2005. Le droit du travail en perspective contentieuse 1993-2003, Ministère de la Justice, Cellule études et recherches.

Ricoeur Paul. 1995. »Herméneutique juridique et herméneutique générale« in Interprétation et droit, ed. Paul Amselek, 175-201, Bruylant, Bruxelles. 
Sunstein, Cass (ed.). 2000. Behavioral Law and Economics, Cambridge University Press, Cambridge.

Troper Michel. 2000. »Une théorie réaliste de l'interprétation«, in Théories réalistes du droit, ed. Olivier Jouanjan, Annales de la faculté de droit, 4: 43-62, Presses Universitaires de Strasbourg, Strasbourg.

Tversky, Amos and Daniel Kahneman (eds.). 1982. Heuristics and Biases, Cambridge University Press, Cambridge.

Tversky, Amos and Daniel Kahneman. 1973. »Availability: A Heuristic for Judging Frequency and Probability, « Cognitive Psychology 5:207-32.

Wacquet Philippe. 2005. »Le droit du travail et l'économie. L'exemple du licenciement économique«, in Antoine Jammeau, Le Droit du travail confronté à l'économie, 115-124, Dalloz, Paris. 